\title{
Moving Forward on Listing Reform
}

\section{AIIFL Working Paper No. 22}

\section{October 2017}

Asian Institute of International Financial Law

Faculty of Law

The University of Hong Kong

www.AIIFL.com

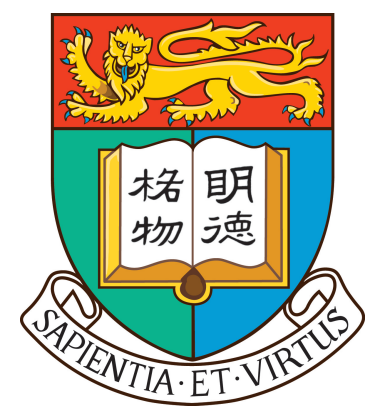

(C) October 2017 the author. All rights reserved. Short text extracts may be quoted without explicit permission provided that full credit including the "C)" notice is given to the source. 


\title{
Moving forward on listing reform
}

\author{
Syren Johnstone*, Nigel Davis ${ }^{* *} \&$ Douglas W. Arner ${ }^{* * *}$ \\ Asian Institute of International Financial Law
}

\begin{abstract}
This paper considers the process of listing reform in Hong Kong. It identifies the primary underlying threads in that process as undertaken to date and queries whether the overarching strategic objectives for market development have been adequately diagnosed. Exchanges compete on a range of factors that are influenced by both public and private interests, which requires a clear policy analysis of developmental objectives as a precursor to regulatory reform proposals. Three Propositions are derived that may assist to reposition the reform debate. It is suggested that if stakeholders take these Propositions on board in earnest, there will be a better prospect for moving forward together on listing reform.
\end{abstract}

\section{Introduction}

Successful market reform requires a dynamic balance between cooperation and challenge that evolves in response to two important sets of considerations. The first is the extant commercial, legal and practical constraints. The second is an objective and encompassing assessment of the strategic opportunities and risks presented by pursuing or not pursuing a course of reform that takes into account the interests of all stakeholders in the market. Whereas the former may tend toward intertia, the latter requires an enabling action.

Hong Kong's dual responsibilities model (DRM) of listing regulation requires this balance to be presided over by the SFC and HKEX ${ }^{1}$ and subjected to the litmus test of the market. The DRM operates at the $2^{\text {nd }}$ and $3^{\text {rd }}$ tiers of the regulatory hierarchy and is ultimately subject to the top-tier, being the Hong Kong Government, which is responsible for the legislation that enables the SFC's and HKEX's undertakings, namely the Securities and Futures Ordinance (SFO).

The first part of this paper briefly considers the recent steps taken by the SFC and the HKEX to reform the governance structure of listing regulation. The second part sets the recent steps in the context of a debate that has been ongoing since prior to the introduction of the SFO. Analysis indicates the recent steps have failed to successfully move the debate on listing reform forward from a repeating set of essentially unchanged issues around which the Hong Kong market has been circling for over 15 years.

The final part builds on the foregoing critique. It identifies common threads in the

\footnotetext{
* Principal Lecturer and Executive Director of the LLM (Compliance \& Regulation) Programme, Faculty of Law, University of Hong Kong; Fellow, Asian Institute of International Financial Law; Solicitor (England \& Wales, Hong Kong, non-practising)

** Principal Lecturer, Department of Professional Legal Education; Deputy Director, Asian Institute of International Financial Law; Former Member of the Listing Committee (2010 to 2014)

${ }^{* * *}$ Kerry Holdings Professor in Law, University of Hong Kong; Co-Founder of HKU's Asian Institute of International Financial Law, LLM (Corporate and Financial Law) Programme and LLM (Compliance and Regulation)

${ }^{1}$ Respectively, the Securities and Futures Commission, and Hong Kong Exchanges and Clearing Limited
} 
ongoing debate that amount to problems in need of better management, and uses the most recent SFC and HKEX proposals as illustrations. It is suggested that the debate needs to be more clearly refocussed on identifying underlying strategic objectives of market development. If real and progressive reform reaches a stalemate at the level of the $2^{\text {nd }}$ and $3^{\text {rd }}$ tiers of Hong Kong's regulatory architecture, the wider economic and social interests in Hong Kong's capital market may become relevant to consider, which may necessitate a firmer topdown policy direction from the $1^{\text {st }}$ tier of the regulatory hierarchy, the Hong Kong Government. The paper concludes by advancing three Propositions for redirecting the debate on listing reform.

\section{Recent steps}

The SFC/HKEX joint consultation commenced in June $2016^{2}$ (Consultation Paper) is part of an ongoing effort to keep Hong Kong's market competitive, which we applaud. Unfortunately, that consultation met with fundamental difficulties as regards market acceptance, including among the SEHK's ${ }^{3}$ own Listing Committee (LC), ${ }^{4}$ and as regards its legal viability, ${ }^{5}$ a concern that had been raised in the Financial Affairs Panel of the Legislative Council. ${ }^{6}$

The recent SFC/HKEX conclusions paper issued in September $2017^{7}$ (Conclusions) is not itself without problems. This section briefly identifies four primary concerns arising out of the newly proposed Listing Policy Panel (LPP) in the context of current regulatory architecture. This will be connected to the historical development in the second section and to the question of market development in the final section of this paper.

First, the proposed LPP is to have "advisory, consultative and steering" ${ }^{8}$ functions that are active, operative and mandatory, and interact with the undertaking of statutory functions. These functions are required to be invoked by the SEHK's Listing Department (LD) from an early stage of it undertaking its statutory function of formulating proposed listing rules. The LD is subsequently required to take into account the LPP's recommendations. ${ }^{9}$ Proposals in which the LPP have an interest are to be presented to the LC, and subsequently the SEHK's Board and the SFC together with the LPP's written views. ${ }^{10}$ While such recommendations are not intended to be binding on the SFC, the HKEX or the LC, ${ }^{11}$ it has previously been pointed out that the SFC's "negative control" and "looming control"12 may, de facto, come to bear considerable influence over the undertaking of statutory functions. This is particularly the case now that the SFC has adopted its frontloaded approach that signals a greater involvement in listing matters traditionally reserved to the SEHK.

\footnotetext{
2 "Joint consultation paper - proposed enhancements to The Stock Exchange of Hong Kong Limited's decision-making and governance structure for listing regulation" SFC/HKEX, June 2016

${ }^{3}$ The Stock Exchange of Hong Kong Limited

${ }^{4}$ Listing Committee submission 2016 (undated); Submission by three Listing Committee members dated 16 November 2016

${ }^{5} \mathrm{~S}$ Johntone, N Davis and DW Arner "A principles-based response to the proposed reform of the governance structure for listing regulation in Hong Kong", University of Hong Kong Faculty of Law Research Paper No. 2016/036 available at https://ssrn.com/abstract $=2867895$

${ }^{6}$ Policy briefing cum meeting of Panel on Financial Affairs on 6 February 2017

7 "Joint consultation conclusions. Proposed enhancements to The Stock Exchange of Hong Kong Limited's decision-making and governance structure for listing regulation" SFC/HKEX, September 2017

${ }^{8}$ Conclusions para 6; SFC press release dated 15 September 2017

${ }^{9}$ Conclusions para 59 (c)

${ }^{10}$ Conclusions para 59 (d)

${ }^{11}$ Conclusions para 59(b)

12 Johnstone, Davis and Arner, op. cit. pp 14-15
} 
How the influence of the LPP will develop over time is hard to predict, however, to the extent that its steerage of policy serves a purpose and is effective (and possibly compelling) there is a risk that other problems may emerge. ${ }^{13}$ Although the LPP would be concerned with "listing policy with broader regulatory or market implications", ${ }^{14}$ "policy" is nevertheless capable of wide interpretation, ranging from very broad principles to more specific constraints on detailed rule making. For example, a policy that allowed weighted voting rights (WVR) could be expressed generally, or expressed at the level of specific requirements such as anti-avoidance measures, sunset clauses, etc. "Policy" could also be interpreted to refer to the application of existing rules - the dynamic and innovative nature of the market means that the SEHK cum LC is constantly being required to develop policies on how to apply existing rules to novel circumstances. Where in this spectrum the LPP's policy steerage mandate is intended to settle, or where it might eventually settle, is not known, leaving the LPP conceptually vague and at risk of undermining the authority and policy-making role of the LC.

Second, the LPP, which replaces the LPC concept proposed under the Consultation Paper, is a "body"15 established "outside"16 of the SFC and HKEX. Although it will be consituted by memorandum of understanding (MoU) arrangements between the SFC and the HKEX, ${ }^{17}$ the LPP possesses a separate identity with specific roles that appear to go beyond merely inter-regulator co-operation and assistance. As such, this makes the LPP a curious entity that sits outside Hong Kong's existing regulatory architecture, despite its involvement in regulatory functions. Although the LPP will operate pursuant to terms of reference, ${ }^{18}$ these can only be operational as there are no legal mechanisms for accountability, oversight or transparency in its undertaking. While the SFC does have the power to form committees, ${ }^{19}$ establish subsidiaries ${ }^{20}$ and enter into MoUs with other regulatory bodies, ${ }^{21}$ it is currently unclear on what basis it would have any power to form or oversee a body such as the LPP. ${ }^{22}$ By way of comparison, the LC was established pursuant to an SFC-HKEX MoU as a sub-committee of the SEHK's board thus giving it a firm legal basis for its existence and its functions. The curious character of the LPP also gives rise to other unaddressed problems. For example, while LPP members may seek the views of their respective organisations, ${ }^{23}$ it is unclear how the secrecy provisions of the $\mathrm{SFO}^{24}$ to which the SFC is subject will operate. It would also be necessary for the SFC to install internal conflict of interest rules that are consistent with best practices globally.

Third, there is some consternation in the market that the Consultation Paper has been followed by the Conclusions, which present a new proposal as a fait accompli without regard to the usual consultation process. While the SFC is not statutorily required to undertake a public consultation in the present

\footnotetext{
${ }^{13}$ Such as the risk that the LPP could be considered a shadow director of important regulatory functions of the LD/Exchange. See Johnstone, Davis and Arner, op cot section 6.2 to 6.3

${ }^{14}$ Conclusions para 6

${ }^{15}$ Conclusions para 6 and 59(a); SFC press release dated 15 September 2017

${ }^{16}$ Conclusions Appendix 1; SFC press release dated 15 September 2017

${ }^{17}$ Conclusions para 59(a)

${ }^{18}$ Conclusions para 7 refers to "how meetings are convened, how they are conducted and how frequently they are held"

${ }^{19}$ S. 8 SFO

${ }^{20}$ s. $5(4)(\mathrm{da})$ SFO

${ }^{21}$ s. $5(1)(h) \& 5(4)(b)$ SFO

${ }^{22}$ The SFC does have wide powers "to take such steps" etc (s.5(1)(a) SFO) but it is doubtful whether that is specific enough to permit the creation of a body outside the SFC. Section 5(1)(0) SFO allows the SFC "to take appropriate steps in relation to the securities and futures industry further to any requirement of the Financial Secretary" etc but the FS has not made any such requirement here ${ }_{23}$ Conclusions para 10

${ }^{24} \mathrm{~s}$. 378 SFO. It is unclear whether the LPP is able to be regarded as a "specified person", for example, under s. 378(15)(c)(iii) SFO
} 
circumstances, its policy, which has been fully vetted in 2002-2003 by the Process Review Panel, ${ }^{25}$ is that it will dispense with public consultation only in very limited circumstances, such as where the proposed changes are "minor and uncontroversial or where a delay in implementing a proposal would not be in the interest of the investing public or the public interest" ${ }^{26}$ The Conclusions therefore sits very uncomfortably with the context of the Consultation Paper having provoked a public response unprecedented in size in Hong Kong's regulatory history.

Finally, it is unclear what benefits the LPP would bring over and above the existing "High-Level Group" (HLG) already established by the SFC and the SEHK pursuant to their 2003 memorandum, ${ }^{27}$ or in what ways the HLG has or has not been effective in fostering policy development. At the time the HLG was established, it was to "strengthen the understanding and communication between" the SFC and the HKEX. ${ }^{28}$ Whether that has worked would appear to warrant assessment, which would require further elaboration as to what the HLG has engaged in or advised on and the level of influence it exercises over regulatory concerns, such as the functions of the LC. It is also unclear whether the LPP is intended as a formalization of the HLG, or if the HLG would cease to operate.

\section{How did we get here}

The DRM of regulating Hong Kong's listed market represents one type of competitive self-regulation. ${ }^{29}$ It rests on the premise that the SEHK via the functionality of the LC understands the problems in the market and how to fix them better than government or statutory regulatory agencies such as the SFC. Over the past thirty years, three important historical reconstructions of this model are:

(1) the government-initiated Hay Davison Report in 1988, which came down in favour of continued practitioner regulation subject to safeguards; ${ }^{30}$

(2) the introduction of the SMLR ${ }^{31}$ and dual filing regime (DFR) concurrently with the SFO becoming effective in 2003, which gave the SFC a measure of oversight of listing applications and listed issuers; and

(3) a set of public consultations and reviews circa the introduction of the SFO undertaken at the initiative of the Financial Secretary (FS) and the FSTB, ${ }^{32}$ particularly (a) the report of the Expert Group ${ }^{33}$ in 2003 in response to the creation in the UK of a listing authority within the regulatory functions of the FSA (now the FCA), ${ }^{34}$ and (b) the FSTB's 2003-2005 consultations on the regulation of listing and scope of the SFC's roles and powers. ${ }^{35}$

\footnotetext{
${ }^{25}$ An independent body appointed by the Chief Executive of the Hong Kong Special Administrative Region to review the SFC's internal procedures

${ }^{26} \mathrm{http}: / /$ www.sfc.hk/web/EN/about-the-sfc/our-role/how-we-function/public-consultation.html (last visited 25 September 2017)

27 "Memorandum of understanding governing listing matters", SFC and SEHK, 28 January 2003, para 5.1

${ }^{28}$ Per Andrew Sheng, Chairman of the SFC, SFC and HKEX joint press release 28 January 2003

${ }^{29}$ See Antony Ogus, Rethinking Self-Regulation, (1995) OJLS 97, at 103

30 "The operation and regulation of the Hong Kong Securities Industry", Report of the Securities Review Committee, May 1988

${ }^{31}$ Securities and Futures (Stock Market Listing) Rules, cap. 571V

${ }^{32}$ Financial Services Treasury Bureau

${ }^{33}$ Report by the Expert Group to Review the Operation of the Securities and Futures Market Regulatory Structure, March 2003

${ }^{34}$ Respectively, the Financial Services Authority, and the Financial Conduct Authority

35 "Consultation paper on proposals to enhance the regulation of listing", 3 October 2003;

"Consultation conclusions on proposals to enhance the regulation of listing", 26 March 2004;
} 
Contemporary discussion in relation to listing reform remains positioned around and to a large extent pinioned by these underpinnings of the past three decades. That it is so is striking given the significant developments in the Hong Kong market in the intervening years including its world ranking in in terms of total market capitalization and it frequently being the largest global market for raising new capital via IPOs. If taken together with China's other main equity markets, Shanghai and Shenzhen, it would be the 2 nd largest equity market in the world. ${ }^{36}$ The composition of listed issuers has also changed dramatically over this period, with a highly significant shift to the listing of Mainland companies such that these firms now account for the majority of market capitalisation and trading. ${ }^{37}$

Yet over the course of these remarkable developments other features of a developed international market have failed to emerge. The position of shareholders has remained unchanged in relation to shareholder rights and remedies despite proposals to develop this area, ${ }^{38}$ and shareholder activism is rare. ${ }^{39}$ The Hong Kong market remains primarily an equities product market that has failed to develop an institutional investor base commensurate with its size, although there is some evidence that this is improving in recent years. ${ }^{40}$ Participation of institutional shareholders is usually regarded as enabling greater depth in the market in terms of better value-testing in the traded market, developing research capabilities among domestic regulated intermediaries, and bringing a positive influence on corporate governance. The influence of institutional investors is further affected by the fact that around half of all listed issuers possess at least one shareholder holding between $30 \%$ and $50 \%$ of the listed capital, with over a third of Main Board issuers having a single majority shareholder. ${ }^{41}$ This failure matters when considered in view of the significantly larger population of issuers coming to the market, many of which are smaller-cap issuers, most of which are from one jurisdiction still undergoing fundamental capital market development, Mainland China, thus presenting limited opportunities for the market or its investors to diversify risk.

One consequence of this context is an increased need to ensure the oversight mechanisms of the DRM are appropriately empowered. While the SFC is given considerable power under the SFO, its powers fall short in various ways of its international counterparts, such as the FCA, the SEC and ASIC. ${ }^{42}$ Although the SFC does have power to make subsidiary legislation, ${ }^{43}$ it is subject to public consultation and the negative vetting of the Legislative Council ${ }^{44}$ - previous attempts to allow the SFC to exercise this power in relation to listing requirements that would operate as subsidiary legislation have been strongly

\footnotetext{
"Consultation paper on proposed amendments to the securities and futures ordinance to give statutory backing to major listing requirements", 7 January 2005

${ }^{36}$ Goldman Sachs Research, "China in Transition," Goldman Sachs, What is Stock Connect, September 2016: available at Twitter: Goldman Sachs, 7 December 2016 (visited on 13 December 2016).

${ }^{37}$ HKEX, "Our Markets": available at https://www.hkex.com.hk/eng/listing/listhk/our_markets.htm (visited on 13 December 2016)

${ }^{38}$ For example, the proposal to introduce class action rights (The Law Commission of Hong Kong, "Report - Class Actions, (May 2012)" has effectively been set aside by the Department of Justice and the HKSAR Government and is no longer listed by the Law Reform Commission as a current project (per its website www.hkreform.gov.hk, as of August 2017); "Consultation conclusions on the proposal to empower the Securities and Futures Commission to initiate a derivative action on behalf of a company", FSTB, 18 November 2003

${ }^{39}$ The current Elliot and Bank of East Asia case being one of those rare examples

${ }^{40}$ Kieran Colvert, "Where were the Investors?," (7 April 2015) Chartered Securities Journal

${ }^{41}$ Research in progress pending publication (S. Johnstone). As the research does not take account of concert parties or associated holdings, the numbers are in reality much larger

${ }^{42}$ Respectively the United States Securities and Exchange Commission, and the Australian Securities and Investment Commission

${ }^{43}$ For example, under s. 36(1) of the SFO in relation to the listing rules

${ }^{44}$ Section 34 of the Interpretation and General Clauses Ordinance (Cap. 1)
} 
rejected. For example, the FSTB's public consultations sought to expand the dual filing regime, a primary objective being to give statutory backing to major requirements of the listing rules and expanding the SFC's powers to encompass civil fining and other powers on the primary targets for breaches of the statutory listing rules. However, the changes proposed did not proceed. The HKEX's position was (1) the only requirements appropriate to be incorporated into the SFO are "the key requirements for the protection of investors and the reputation of the market", (2) the proposed rules lacked the clarity and certainty required of legislative provisions, (3) the principle underlying the DRM should be that the HKEX "administers and interprets the Listing Rules and the SFC enforces those requirements which receive statutory backing" ${ }^{\prime 4}$ and (4) it was the role of the legislature, not the SFC, to set out the main requirements and that subsidiary legislation falling with the powers of the SFC should be restricted to filling out the details. ${ }^{46}$ To date, only the price-sensitive information provisions of the Listing Rules have been given statutory effect through the introduction of Part XIVA SFO in 2013.

\subsection{Different means of exercising the regulatory mandate}

The difficulties in finding pathways for reform that are acceptable to different stakeholders has led to the SFC seeking both ex post and ex ante means of establishing more effective methods of exercising its overarching regulatory mandate.

The SFC has become progressively more active in the courts over the course of the last decade in bringing wrongdoing directors and issuers to account via its powers under the SFO, ${ }^{47}$ culminating in the more recent identification of corporate wrongdoing as one of its top enforcement priorities. ${ }^{48}$ Such actions are squarely based in a proper exercise of powers given to it, and are not controversial as regards the structural relationship between the HKEX and the SFC - the HKEX as a matter of policy recognizes the SFC as a statutory enforcer of the law. ${ }^{49}$

It is generally recognized that the costs of such ex post enforcement are more costly to a market than ex ante enforcement ${ }^{50}$ and the SFC has been pursuing two ex ante approaches in recent years to seek to reduce that cost.

First, over the period 2011 to $2013^{51}$ the SFC laid the groundwork for bringing an intensified spotlight on the work of sponsors as an important gateway mechanism for ensuring the quality of listed issuers, a thread that runs back to concerns expressed in the Hay Davison report. This is entirely consistent with the SFC's role as a regulator of intermediaries. The SFC has laid some emphasis on the connection between sub-standard sponsor work and listed company fraud. ${ }^{52}$ However, far less is said about the effect of sub-standard sponsor work on the

\footnotetext{
45 "Combined Submission of HKEX in Response To The FSTB and SFC Consultation Papers On Proposals to Give Statutory Backing To Major Listing Requirements" 24 March 2005, para 1.4-1.5

46 "Combined Submission of HKEX in Response To The FSTB and SFC Consultation Papers On Proposals to Give Statutory Backing To Major Listing Requirements" 24 March 2005, para 1.5(a)

${ }^{47}$ In particular, ss. 212, 213, 214, 277 and Parts XIII and XIVA of the SFO

${ }^{48}$ Per speech of Thomas Atkinson, SFC Executive Director, Enforcement, at the 7th Pan Asian Regulatory Summit, 9 November 2016

49 "Enforcement of the listing rules - policy statement", HKEX, first issued 13 September 2013, revised 17 February 2017

${ }^{50}$ For example, see John Coffee, "Law and the Market: The Impact of Enforcement" (2007) Columbia Law and Economics Working Paper, No. 304

${ }^{51}$ Particularly the "Report on sponsor theme inspection findings", SFC, March 2011 and the SFC's

"Consultation Conclusions on the regulation of IPO sponsors", 12 December 2012

${ }^{52}$ Per speech of Thomas Atkinson, SFC Executive Director, Enforcement, at the 8th Pan Asian Regulatory Summit, 11 October 2017
} 
ability of a viable, non-fraudulent listing applicant to obtain a listing in an efficient and predictable manner consistent with international expectations. The reputation of the market is negatively affected in both instances. Whereas the former may cause investor losses and grabs media headlines, the latter is a more veiled danger that may cause lost opportunities or an increased implied cost to the issuer of obtaining a listing. The success or failure of the regulatory agencies can be separately assessed in relation to each of the foregoing.

Second, more recently, the SFC has signalled a greater preparedness to utilize its power under s. 6 SMLR as a means of moving from goalkeeper into the playing field ${ }^{53}$ and placing greater emphasis on earlier, more targeted intervention. ${ }^{54}$ This power has only rarely been used, ${ }^{55}$ and indeed from the outset of the power being given to the SFC it was envisaged that, because the SFC and HKEX would be working together to identify serious issues at the beginning of the listing application process, "a statutory objection at the end of the process would not normally be necessary". ${ }^{56}$ The SFC's present stance has therefore led to concern among some market participants that the power may be inconsistent with the DRM because it is being used beyond its original purposes as a "reserve power". ${ }^{57}$

\section{Repositioning the discussion on listing reform}

It is clear from the foregoing overview that the current debate over listing reform turns on two fundamental questions.

First, what is the proper role of the SFC in relation to the listed market? The SFC's role is at present defined by the SFO and the actions it is permitted or expected to engage in. Significant emphasis is typically placed on the SFC's role as an enforcement regulator tasked to protect investors, a role that has been reinforced in the Courts. ${ }^{58}$ However, the debate less commonly finds focus on the requirement that, when pursuing its objectives and functions, ${ }^{59}$ the SFC is statutorily required to have regard to, inter alia, facilitating innovation with financial products and the development of Hong Kong as an internationally competitive market. ${ }^{60}$ This implicitly identifies a need for the SFC to balance sectoral cum vested interests with the public role of the listed market and to recognize broader social interests as a legitimate stakeholder in its development. ${ }^{61}$ To put this another way, any applied interpretation of shareholder protection, market integrity and market development must be balanced having

\footnotetext{
${ }^{53}$ Per the analogy suggested by Carlson Tong, Chairman of the SFC, as quoted in the South China Morning Post, 3rd July, 2016

${ }^{54}$ Per Ashley Alder, SFC CEO, "Front-loaded, transparent and direct: A new approach to regulation for changing markets", speech given at the HKSI Institute Roundtable Luncheon Series", 13 July 2017. Available on the SFC's website. See also "SFC Regulatory Bulletin: listed corporations" Issue No. 1 July 2017

${ }^{55}$ In relation to the listing application of China Nonferrous Gold Limited in January 2015. More recently, it has used the power in relation to the listing applications of Alpha Era International Holdings Limited in July 2017, and Soar Group Holdings Limited in June 2017 (the latter of these was appealled but the appeal was subsequently withdrawn - see www.sfat.gov.hk)

56 "Smooth implementation of dual filing", SFC, 29 May 2003

${ }^{57}$ See paragraph 28 of the SFC's A Consultation Paper on the Securities and Futures (Stock Market Listing) Rules and the Securities and Futures (Transfer of Functions - Stock Exchange Company) Order, May 2002

${ }^{58}$ For example, the SFC's role "to protect the investing public which is an important objective of the SFO" Securities and Futures Commission v. Tiger Asia Management LLC and Others (2012) HKCA 85, at para 35 and positioning the SFC as a "protector of the collective interests of the persons dealing in the market" Securities and Futures Commission v. Tiger Asia Management LLC and Others (2013) HKCFAR 324, at para 16

${ }^{59}$ Ss. 4 \& 5 SFO

60 S. $6(2)(a) \&(b)$ SFO

${ }^{61}$ For a discussion, see: DW Arner, BFC Hsu, SH Goo, S Johnstone and P Lejot "Financial Markets in Hong Kong: Law and practice", OUP, 2016, 10.05-10.11
} 
regard to all stakeholder interests in the market.

The foregoing considerations give rise to the second question, whether the SFC's role should develop, and if so how and why? Given that the rule of law is a centerpiece of Hong Kong's system and prevailing culture, any proposal to develop the SFC's role must occur within that framework. In the absence of legislative reform, one route would be for the SFC to propose legislation subsidiary to the SFO, however, this is not an unfettered power and is in reality subject to political influences. Alternatively, one might seek to interpret the law to achieve a sought-after objective, however, this should be undertaken with considerable caution to preserve the integrity of the regulatory system, its transparency and predictability - the latter requirements being particularly important to prospective issuers considering Hong Kong as a potential listing venue.

It would be a blinkered vision to position specific questions of listing reform as being matters of law. Rather, listing reform is ultimately subject to, and driven by, an assessment of substantive matters that are essentially value-laden. Among others: What development needs are not being met? Who has an interest in such development? How urgent or important are these needs as compared to others? What are the alternative means of meeting these needs? What are the potential outcomes/risks of each alternative? How is the risk of introducing a development to be measured against the risk of not doing so?

Identifying the relevant questions and seeking their resolution with a view to implementing market development is dependent on some form of consensus mechanism between stakeholders. While this may seem an impossible task in a factionalized landscape, it is nevertheless essential. It is suggested that there are two precursors to consensus.

The first is agreeing a common, objective methodology for assessing reform proposals, failing which outcomes will be largely dictated by entrenched positions that promote stagnation. For example, should assessment be undertaken on a cost-benefit analysis, as is expected of the SEC with regard to proposed changes in regulation in the United States? As appealing as that may appear, such analyses have significant drawbacks. They are time consuming, expensive to undertake and do not always result in an agreed (i.e. unchallenged) outcome. ${ }^{62}$ They are normally oriented around a positive proposal to do something, as opposed to the potential cost of preserving the status quo through inaction. And they ultimately incorporate value-based assessments because they necessarily require assumed priorities or objectives.

The second precursor, which therefore accompanies methodology, is establishing shared objectives. In the context of the SFC's role in listing reform, this returns one to the issue of balancing protection with development and the question of how to define that balance and who should be defining it.

It is useful to cast these somewhat abstract considerations in the context of the issues presently being discussed in relation to the market: HKEX's proposal for a New Board (Concept Paper), ${ }^{63}$ WVR, and the SFC's front-loaded use of s. 6 SMLR. While not seeking to make a substantive submission on these issues, observations can be made that help identify some key threads relevant to the

\footnotetext{
${ }^{62}$ The SEC has had some notable struggles in this regard, for example, the SEC'S proxy access Rule 14a-11, successfully challenged in court - see Business Roundtable And Chamber Of Commerce Of The United States Of America v. SEC, United States Court of Appeals, For The District Of Columbia Circuit, Decided July 22, 2011, No. 10-1305

63 HKEX "Concept paper. New Board" June 2017
} 
process of reform. These threads can alternatively be read as problems in listing reform to date that are in need of better management.

\subsection{Whether regulatory architecture is the correct starting point}

The fundamental question that has resurfaced following the Consultation Paper is whether the DRM works or should be replaced by a listing authority embedded within the SFC. The discussion of the merits or otherwise of such a change is a far reaching one that contemplates a fundamental change to regulatory architecture. Any comparison with the experiences in other markets would need to be significantly updated since the 2003 Experts Report in order to establish whether such a change would bring any benefit to Hong Kong. This is essential given the developments in the Hong Kong market since that time, which includes the composition of listed issuers as well as the body of case law developing in tandem with the SFC's role as a corporate enforcer. It also requires a consideration of those matters that have remained essentially unchanged, such as shareholder rights. In the absence of such a review, calls for a listing authority appear premature - it is far from certain whether such an alternative model would have worked better than the current model under which Hong Kong has enjoyed a considerable measure of prosperity. Calls for a fundamental change in regulatory architecture possibly also serve as a distraction from identifying other mechanisms that could work to stimulate change from within the DRM. In short, insofar as a change to regulatory architecture is not a currently implementable solution, its relevance to the present issues may be limited. Moreover, a change to regulatory architecture necessarily requires the involvement of the Legislature, and this is discussed in section 3.4 below.

\section{2 "Order dependence" and the strategic objectives for the capital market}

The present listing reform issues do not themselves represent underlying strategic objectives for the long term development of Hong Kong's capital market. The HKEX's Concept Paper is a case in point. Competition from other markets, particularly New York, for new listings is a central concern and in effect positions Hong Kong's continued success in terms of competing in relation to pre-profit companies, companies with WVR structures, and Mainland companies listed elsewhere. ${ }^{64}$ However, markets also compete on a range of other issues, such as the transparency, efficiency and predictability of the listing process. They also compete on the costs and potential liability of being listed in a particular venue, for example, while the introduction of the Sarbanes-Oxley Act of 2002 may have helped improve investor confidence, it also sufficiently increased liability and compliance costs for listed companies to create a competitive disadvantage. ${ }^{65}$ So the first question is, on what items should Hong Kong choose to compete?

Size does matter - permitting WVR structures and pre profit companies to list would facilitate that - but simply increasing the traded size of a market size patently is not synonymous with market development. The substantive proposals of the Concept Paper serve to draw the listing reform debate toward its specific details, on which opinion goes both ways. Is the New Board just another GEM-inwaiting? Are the purposes sought to be achieved by the New Board better sought through the existing Main Board? Are professional investors investing in WVR adequately protected? Does the abandonment of the one-share-one-vote principle (OSOV) in one part of the market represent the start of a slippery slope into which other parts of the market will eventually slide?

\footnotetext{
${ }^{64}$ Concept Paper section 2.3

${ }^{65}$ It also led to an increase in the number of companies delisting (from 48 in 2003 to 80 in 2004) and a significant decrease in the number of foreign issuers coming to the U.S. market as the venue for a listing
} 
These specific concerns in fact touch on a number of interconnecting issues that, it is suggested, are more properly issues for consideration in relation to strategic market development, such as the following:

Would the New Board promote an increased participation of international institutional shareholders that would bring a wider set of benefits to the Hong Kong market? ${ }^{66}$ If so, how? Is the New Board the only alternative to achieve this? Is WVR the only means by which this can be achieved? What are the alternatives? And, if one does lean in the direction of accepting WVR structures, is it necessary to consider what alternative protections are available following the removal of OSOV upon which the present system is based? Does it imply that the Law Commission's 2012 proposals to introduce class action rights (CAR) ${ }^{67}$ must be reinvigorated? Would the SFC's role as an enforcer of collective interests be adequate in the absence of developing CAR? ${ }^{68}$ If not, what alternative protections are available? Will WVR present further challenges to maintaining good corporate governance standards in the public market? If the market is limited to professional investors, should the SFC's powers under the SMLR be repositioned to let the market decide? Does or should this represent a shift away from Hong Kong's hybrid disclosure plus merit-based regulation toward a more purely disclosure-based regulation? If so, is Hong Kong's overall system of laws and regulatory protections ready for a more purely disclosure-based system? And if institutional investors do not develop in response to permitting $W V R$, are shareholders exposed to a market that may suffer from inadequate value-testing and research facilities?

Clarity is needed to understand whether such interconnected questions precede and lead the debate on listing reform, or whether they are led by and follow a debate that is primarily driven by extrinsic factors - this relationship might be termed "Order Dependence".

The discussion around WVR serves as a useful illustration of Order Dependence. It is notable that in the extensive discussions about WVR that have taken place over the last 4 years ${ }^{69}$ there has been little or no reflection on why stock exchanges in the United States permit WVR structures. Contrary to what appears to be a commonly held given, WVR structures did not arise because of a disclosure based system that was protected by $\mathrm{CAR}^{70}$ nor was it due to any special characteristics of tech companies. While WVR structures had been popular in the relatively unregulated era of the 1920s, following the Depression OSOV was restored. WVR again emerged in the 1980s as companies sought to make themselves takeover proof. The NYSE ${ }^{71}$ only abandoned OSOV following the threat by General Motors in 1984, a highly significant company at the time, that it would move to Nasdaq if NYSE did not acquiesce to its request. ${ }^{72}$ Nasdaq and the American Exchange, both of which represented a growing competitive threat to

\footnotetext{
${ }^{66}$ As discussed in section 2 above

67 "Report - Class Actions, (May 2012)" The Law Commission of Hong Kong. The proposal has effectively been set aside by the Department of Justice and the HKSAR Government and is no longer listed by the Law Reform Commission as a current project (per its website www.hkreform.gov.hk, as of August 2017).

${ }^{68}$ S Johnstone "A flawed debate", International Financial Law Review, May 2015, 38-39. Available at SSRN: https://ssrn.com/abstract $=2811028$

${ }^{69}$ Primarily following the rejection in 2013 of Alibaba's proposed WVR-structure listing.

${ }^{70}$ While most CAR actions do arise in respect of disclosure problems or fraud (see "Securities Class Acting Filings 2013 Year in Review", Cornerstone Research and the Stanford Law School Securities Class Action Clearinghouse, at page 7) an abuse of power involving a breach of of fiduciary duty to the company is primarily a matter for a derivative action taken on behalf of the company

${ }^{71}$ The New York Stock Exchange

$72 \mathrm{GM}$ planned to issue a second class of shares with one-half vote per share
} 
the NYSE at the time, did permit WVR. ${ }^{73}$ Bowing to commercial pressure, the NYSE sought the SEC's approval to relax its own OSOV listing requirement - in response, the SEC in 1988 adopted Rule 19c-4, a "Disenfranchisement Rule"74 that prevented WVR structures. However, the rule was successfully challenged in court $^{75}$ and has since been replaced with a provision that merely prevents conversions from OSOV to WVR structures. ${ }^{76}$

Several lessons can be learned from the foregoing. First, that the SFC's concerns about WVR has in fact already been played out in the field by the SEC. Second, there was a failure of legality: the SEC's 1988 rule was ultra vires. ${ }^{77}$ Third, and importantly for the purposes of illustrating Order Dependence, the fundamental dynamic that drove the WVR issue was essentially a tug-of-war between private interests ${ }^{78}$ and a public market policy in which the former dominated the latter. The implication of the relationship between private and public interests shall be returned to below. Finally, it should be asked, as an empirical matter, to what extent did the NYSE's adoption of WVR contribute to its continued success.

Clearly there are developmental objectives beyond competitiveness. In this respect, perhaps the most important relates to the ability of Hong Kong's markets to provide necessary channels for raising capital to support the development of innovation and the real economy, here and elsewhere.

\subsection{Process of undertaking listing reform}

It has already been noted above that development requires some form of consensus between stakeholders. This first requires the identification of the relevant stakeholders. While this may seem obvious, even trite, it should not be underestimated. For example, it was surprising that the preparation of the Consultation Paper did not involve consultation with the LC. This led to both the LC as a body, as well as a group of members from within the LC, issuing differing views on the viability of the proposals. ${ }^{79}$ Given the LC's important role in the listing process, it would have seemed reasonable, if not highly desirable, to seek access to its expertise, not least because the LC's functionality was a subject of the Consultation Proposal. Moreover, the voices of its members do carry influence in the financial community. Failing to include relevant stakeholders may run counter to the idea of engagement with the market and can lead to failures to take an adequate sweep of attendant concerns and put potential collaborators off-side. Involvement is no guarantee of agreement, but it does run a higher possibility of paring down proposals to what can be accepted and work.

Putting aside the influence of dominant economic entities has in the past been

\footnotetext{
${ }^{73}$ Including no-vote shares (as recently seen in the Snap IPO). See W Bratton "Let dual-class companies list abroad" in "Dual-class stock: Governance at the edge", Shareholder Value, Third Quarter, 43. (2012)

747 C.F.R. § $240.19 c-4$ (1988). Voting Rights Listing Standards; Disenfranchisement Rule, 53 Fed.Reg. $26,376,26,394$ (1988)

${ }^{75}$ The Business Roundtable, Petitioner, v. Securities and Exchange Commission, Respondent, U.S. Court of Appeals for the District of Columbia Circuit - 905 F.2d 406 (D.C. Cir. 1990). See also Grant M. Hayden \& Matthew T. Bodie, One Share, One Vote and The False Promise of Homogeneity, 30 Cardozo Law Review, 471. (2008)

7617 CFR 240.19c-4 (as amended 2005)

77 The legal provisions relied on by the SEC did not provide it with the authority to make the rule. See the Business Roundtable case, op. cit.

${ }^{78}$ Although General Motors was a public listed company, its actions reflect the interests of a corporation pursuing its own objectives without regard to wider public market concerns

${ }^{79}$ Listing Committee submission 2016 (undated); submission by three Listing Committee members dated 16 November 2016
} 
difficult. ${ }^{80}$ The difficulty of aligning different interests and the powers of the SFC and HKEX being constrained (as noted above) is in part why reform proposals have had a patch-like quality to them. Both the Consultation Paper and the Conclusions seek to develop the oversight of the listed market from within the narrow space for movement provided by the SFO and both present difficulties: it has not worked to align stakeholder interests, and it gives rise to legal cum regulatory problems that are important to get right. In the context of rule of law, any proposal that does not sit within the legal framework in effect serves as a distraction from and an obstruction to meaningful forward progression. It also runs the risk of leaving aspects of the system exposed and unsatisfactorily regulated, as the SEC had found with WVR. Patch-like bricolage also risks leaving the regulatory system looking unclear, uncertain as to its application and unpredictable, particularly when looked at from the perspective of a foreign issuer considering a listing on the Hong Kong market to access Chinese capital, as opposed to tapping another market for capital.

The SFC's recent engagement of its s. 6 SMLR powers may be a case in point. There is currently a division of opinion in the market as to whether it amounts to using the power in a manner beyond its original intent as a "reserve power". ${ }^{81}$ In support of the SFC's use of the power, it can be argued that if one puts aside the SFC's "goalkeeper to playing-field" rhetoric, the power is, prima facie, in accordance with the intent of the legislative provisions insofar as a power does not cease to be reserve in nature simply because it is used more actively. On this basis, one might even choose to critique the SFC as to why it has not used it more actively in the past.

The issue is really the qualitative employment of the s. 6 power and the extent to which it is consistent or at variance with the DRM/DFR. For example, objecting to a listing application based solely on the applicant's prospects or sustainability would be a qualitatively different use. In contrast, it is less clear whether the SFC's new process of writing directly to the sponsor directly with its queries instead of the long standing practice of providing them to the SEHK, is qualitatively different. While some may regard this as bypassing the SEHK's role as the frontline regulator of listing applications and to that extent inconsistent with the DRM, given that the SEHK's past practice was in general merely to photocopy and forward the SFC's queries, this new process may be more emblematic than substantive.

What is of greater significance under the SFC's new approach is that its queries may be concerned not only with the contents of the draft prospectus but also directed to the sponsor to seek details of the due diligence steps it has undertaken. This is significant because, although sponsor work does have a bearing on the quality of disclosures, the SMLR is only concerned with the listing applicant, not the sponsor. ${ }^{82}$ Queries directed to the sponsor's work undertaking therefore appear to go outside the scope of the SMLR's concerns and are more properly explained as an exercise of the SFC's mandate to supervise intermediaries (i.e. sponsors) under Part VIII SFO. One might ask what difference does it make, between which route the SFC uses to interrogate a sponsor's work undertaking. In response it may be pointed out that regulatory clarity, particularly as regards the intended purposes of the DRM, is muddied. Any exercise of Part VIII powers is not a concern of the SEHK or the listing

\footnotetext{
${ }^{80}$ Dominant economic entities continue to exert influence, over the past two decades the financial system is becoming increasingly rule based and transparent. See DW Arner at al, op. cit., para 2.20 ${ }^{81}$ See section 2.1 above

82 S. Johnstone, A Da Roza and N Davis, "Deconstructing sponsor prospectus liability" Hong Kong Law Journal, Vol 46(1) 2016, 255-285, 265. Abstract available at SSRN: https://ssrn.com/abstract $=2811000$
} 
applicant, ${ }^{83}$ and might invoke secrecy concerns. ${ }^{84}$ In contrast, queries under the DFR route brings focus to the listing applicant, which takes one back to the concern, noted in section 2.1 above, about the more veiled dangers to the market of suspecting the problem rests in the quality of the listing applicant.

Where entrenched interests have stultified reform in a manner that neither the SFC nor the HKEX can resolve through stakeholder involvement, or where the efforts of regulatory agencies to work together within the existing framework have created problems or complexities of one sort or another, another mechanism of reform is available that amounts to direction.

\subsection{What is the appropriate mainspring of development}

In the absence of law reform, the listing reform debate has to date been primarily undertaken at the $2^{\text {nd }}$ and $3^{\text {rd }}$ tiers of Hong Kong's regulatory architecture - the SFC and the HKEX. Originating and implementing development at these tiers of Hong Kong's three-tier regulatory architecture is consistent with what was envisaged with the introduction of the SFO in 2003 and Hong Kong's free market economy ${ }^{85}$ in which the top tier - the HKSAR Government - has maintained its historically adopted policy of "positive noninterventionism". ${ }^{86}$

The Government and its agencies established the essential framework of the reform debate via the three key initiatives identified in section 2 above. The $2^{\text {nd }}$ and $3^{\text {rd }}$ tier agencies have been circling these issues for over a decade without significant progress. Nor has there been progress in establishing new approaches to reform, for example, as regards agreeing the underlying strategic objectives of achieving market development ${ }^{87}$ and how best to pursue them. This has, over time, led to a growing concern that stalled progress, and the lack of a clear development pathway, may be impacting not only on the success of the market per se but also on the interests of the largest stakeholder group in the market, namely, Hong Kong's wider social and economic interests. This requires a recognition at all three tiers that capital markets ultimately exist to serve the broader community and the economy, not merely the persons engaged in market activity on a daily basis. The Order Dependence of the listing reform debate is highly relevant to consider here - is it being driven by private interests (as was seen with WVR in the United States ${ }^{88}$ ) as opposed to public market policy development? If the foregoing considerations are causes for concern, one might query whether the $2^{\text {nd }}$ and $3^{\text {rd }}$ tier agencies (including stakeholders in these tiers) are best suited to undertake the reform task, and go on to suggest that development may require returning the task to the top tier, which is more properly concerned with the wider public interest. This would need to go beyond the FSTB ${ }^{89}$ and the $\mathrm{FS}^{90}$ as neither has any specific powers under the SFO in relation to listing reform.

\footnotetext{
${ }^{83}$ The Part VIII route brings focus to the ongoing work of the sponsor indepently of any particular listing applicant, however, if the SFC took regulatory measures against the sponsor this might cause the sponsor to be unable to continue an active engagement for a listing applicant

${ }^{84}$ If the SFC is conducting a supervisory inspection under Part VIII this would normally be regarded as subject to s. 378 SFO

85 Milton Friedman, "The real lesson of Hong Kong" (1997), Magazine of the University of Chicago Booth School of Business, Fall, and "Hong Kong wrong", Wall Street Journal 6 October 2006

${ }^{86}$ A term coined by Sir Philip Haddon-Cave to describe the approach of John Cowperthwaite, the Financial Secretary of Hong Kong from 1961 to 1971

${ }^{87}$ Such as those discussed in section 3.2 above

${ }^{88}$ See section 3.2 above

${ }^{89}$ The FSTB reflects the Government's "broad policy interest and concern in the development of Hong Kong's financial markets as part of Hong Kong's economy". Robert G Kotewall and Gordon CK Kwong, "Report of the Panel of Inquiry on the Penny Stocks Incident," (September 2002): available at http://www.info.gov.hk/info/pennystock/reporte-full.pdf (visited 7 November 2016) para 3.4.
} 
While a firmer top-down $1^{\text {st }}$ tier policy direction may be beneficial, or even necessary, to move Hong Kong forward from a repeating cycle of issues, it ultimately remains a question of whether the social needs of Hong Kong are sufficient to warrant intervention by the Government. Such an intervention would appear necessary if the SFC and/or HKEX are insufficiently enabled to resolve the issues within the existing framework. As the HKEX itself noted in its 2005 submission to the $\mathrm{FSTB}^{91}$ it is the role of the Legislature to set out the main requirements that should govern the Hong Kong market. For example, when debating the question of reforming the Singapore Companies Act to permit public companies to adopt WVR structures, its Parliament was primarily concerned with the need to "maintain the relevance of Singapore as a financial hub and to maintain its competitiveness and attractiveness relative to its competitors. "92 This led to changes in the Companies Act; ${ }^{93}$ however, the corresponding listing reform remains under discussion.

The foregoing considerations beg several questions: whether Hong Kong's toptier is capable of conducting an in-depth, impartial review leading to proposals that are forward-looking and in line with the foreseeable direction and needs of the development of Hong Kong's financial market; whether the Legislature and Government are capable of providing strategic vision and leadership; and, given some of the notable failures in the past, ${ }^{94}$ whether any such proposals could be implemented.

Reflecting some of the above concerns, it is noteable that the newly established Financial Leaders Forum in its first meeting discussed the recent developments in the listing reform debate against the context of the future of Hong Kong's listing platform. ${ }^{95}$ Whether it is time to seek from the Legislature greater clarity of direction that would serve to move the market forward ultimately rests on whether entrenched interests are willing to engage in meaningful consensusseeking within the $2^{\text {nd }}$ and $3^{\text {rd }}$ tiers.

\subsection{Three Propositions}

The objective of this section 3 being to identify some key underlying threads that may assist to reposition the debate on listing reform, the foregoing considerations might be distilled into three propositions with attendant questions, as follows.

The Commercial Proposition: It is necessary to identify the strategic policybased objectives for market development as distinct from business cum economic pressures of an essentially private nature. Only then can these two sets of issues be properly assessed, reconciled and developed.

Attendant questions: What metric should be used to assess the risks to different stakeholders in the listed market of engaging (or not engaging)

\footnotetext{
${ }^{90}$ The FS has responsibility for legislation and policy on matters concerning the securities and futures market. The SFC is required to advise the FS on such matters per s. 5(1)(q) SFO (see also s.12 SFO) but this does not amount to a power in the hands of the FS

${ }^{91}$ op. cit.

${ }^{92}$ Singapore Parliamentary Debates, Second Reading (Response) Speech on the Companies (Amendment) Bill, 8 October 2014

${ }_{93}$ The new section 64A if the Companies Act (cap. 50) allows public companies to issue shares of different classes

${ }_{94}$ For example the FS/FSTB consultations discussed in section 2 including in particular the 2003 Expert Report, following which the FS had announced that a statutory listing authority would be established but subsequently recanted

95 The first meeting was held on 30 Augist 2017. See

http://www.news.gov.hk/en/categories/finance/html/2017/08/20170830_155550.lin.shtml
} 
in a particular listing reform that gives precedence to one of the above two sets of issues? Which of the three tiers are capable of establishing a long term vision for market development?

The Regulatory Proposition: Any proposed reform originating from the $2^{\text {nd }}$ or $3^{\text {rd }}$ tiers must be consistent with powers given to regulatory agencies. Where those powers are inadequate to introduce reform considered necessary or desirable for market development, then it is necessary to go back to the law makers.

Attendant questions: How should the SFC's development mandate be executed, in particular, how should the protection of shareholders be balanced with the interests of all stakeholders in developing the public market? At what junctures should one trump the other, and what is the correct agency to make that decision?

The Consensus Proposition: There is ample scope for consensus building within the $2^{\text {nd }}$ and $3^{\text {rd }}$ tiers of Hong Kong's regulatory architecture. However, if consensus fails to form leading to stagnation in market development, stakeholders in the $2^{\text {nd }}$ and $3^{\text {rd }}$ tiers must reconcile themselves to receiving direction from the top tier.

Attendant question: At what tier of Hong Kong's regulatory architecture are different types of reform question most appropriately undertaken where sufficient consensus fails to form?

These three Propositions clearly are not themselves solutions to the current problems in listing reform. Rather, it is suggested that if stakeholders in the reform debate take these Propositions and attendant questions on board in earnest, there will be a greater possibility for moving forward together on listing reform. ${ }^{96}$

\footnotetext{
${ }^{96}$ The authors would like to thank for their comments on an earlier draft Simon Harding and another anonymous reviewer; the views expressed and any errors remain those of the authors
} 